\title{
Knowledge of Diabetic Patients about Foot Care
}

\author{
Ashia Khatun ${ }^{1}$
}

\begin{abstract}
Objective: The present study was undertaken to determine the level of knowledge and practice of foot care among diabetic patients.

Methods: This cross-sectional study was conducted in the Faculty of Public Health, Atish Dipankar University of Science \& Technology, Dhaka over a period of 6 months. A total of 100 patients of both sexes with type I and type II diabetes for at least six months were the study population. The level of knowledge measured on a 0-4 Likert Scale, where 0 means 'grossly dissatisfied' and 4 'highly satisfied' with 'partially satisfied' 1, 'more or less satisfied' 2, and 'satisfied' 3 in between them. First the level of knowledge was assessed for every discrete question pertaining to knowledge. Then all these scores were added together to ascertain the overall level of knowledge. Data were processed and analysed using computer software SPSS (Statistical Package for Social Sciences), version 11.5.

Result: This study showed that $7 \%$ of diabetic patients were below 40 years, $23 \%$ between 40 - 50 years, $43 \%$ between 50 - 60 years and the remaining $27 \% 60$ or $>60$ years old. Female patients were predominant giving a female to male ratio of roughly $2: 1$. About $60 \%$ of the patients were rural residents and rest $40 \%$ urban. Over two-thirds (68\%) of the patients belonged to middle class, $29 \%$ to lower class and $3 \%$ to upper class. Forty five percent of the patients were below SSC level educated, $8 \%$ SSC, $7 \%$ HSC and $13 \%$ graduate and higher level educated. Twenty seven percent of patients were illiterate. Assessment of knowledge about foot care revealed that over $8 \%$ of the respondents' knowledge about foot care was highly satisfactory, $42 \%$ satisfactory, $40 \%$ more or less satisfactory and $8 \%$ poor level of knowledge. However, practice level about foot care was inappreciably low. Over half (52\%) of the respondents inspected their feet regularly, $42 \%$ washed feet with warm water, $46 \%$ trimmed toe-nails straight across, $63 \%$ measure feet before buying foot-wear and only $8 \%$ received advice from doctors before buying them.
\end{abstract}

Conclusion: The study concluded that diabetic patients are aware of their foot care. They also have good knowledge about how to take care of their feet. But they are often reluctant to translate it into practice. It is perhaps, they do not have the knowledge about the consequences if practice is lacking.

Key words: Knowledge, diabetic patients and foot care.

\section{INTRODUCTION}

Diabetes mellitus (DM) is believed to be the commonest and most devastating chronic disease in human history. It has afflicted mankind for thousands of years and continues to do so at an exponential rate. ${ }^{1}$ It is being increasingly recognized as a global epidemic with devastating humanitarian, social and economic consequences. The rise in prevalence of DM is likely to bring a concomitant increase in its complications among diabetic patients. The important complication of DM are the foot problems; these complications constitute an increasing public health problem and are a leading cause of admission, amputation and mortality in diabetic patients. The prevalence of diabetic foot ulcer (DFU) ranged between $1.0 \%$ to $4.1 \%$ in the United States (US), $4.6 \%$ in Kenya, and $20.4 \%$ in Netherlands. ${ }^{2}$

In 2000, Bangladesh had 3.2 million people with diabetes and was listed globally at $10^{\text {th }}$ position, which would occupy the $7^{\text {th }}$ position with 11.1 million

\section{Authors' Information:}

${ }^{1}$ Ashia Khatun, Lecturer, BIRDEM Nursing College, BIRDEM General Hospital, Shahbag, Dhaka-1000.

Address of Correspondance: Ashia Khatun, Lecturer, BIRDEM Nursing College, BIRDEM General Hospital, Shahbag, Dhaka-1000, Mobile: 01716-634868. 
diabetics in 2030. ${ }^{3}$ The prevalence of diabetes in Bangladesh was $5.2 \%$ (urban $6.9 \%$ and rural $4.3 \%$ ) in $1994-95$ which increased to $9 \%$ (urban $11.2 \%$ and rural $6.8 \%$ ) in 2003-04. ${ }^{4}$ The level of practice of the foot care principles are poor and foot problems account for a significant hospital admissions of patients with diabetes.

The etiology of the foot problems in Bangladesh is primarily peripheral neuropathy; peripheral vascular disease being rare. ${ }^{1}$ It is really regrettable that surgical intervention or amputation is frequently required in our country for a neuropathic foot, which is entirely preventable. An understanding of the causes of these problems enables early recognition of patients at high risk. A study on self care of diabetic foot has not been conducted previously in our country. Therefore this study aims to assess the level of knowledge and practice of foot care among patients with chronic diabetic foot ulcers.

\section{MATERIALS \& METHODS}

This cross-sectional study was conducted in the Faculty of Public Health, Atish Dipankar University of Science \& Technology over a period of 6 months between January 2012 to June 2012. Data were collected from diabetic patients attended at Out-patient Department of BIRDEM Hospital, Shahbag, Dhaka. The following enrollment criteria were applied for selection of patients. Patients of both genders with type I and II diabetes for at least six months were included in the study. Patients who developed foot ulcers or DM patients unable to answer the questions because of altered mental state were excluded from the study. A total of 100 patients meeting the eligibility criteria were consecutively included in the study. Patients' level of knowledge was measured using Likert Scale. To assess the level of knowledge of the respondents about foot care, there were a number pertinent questions. As there were more than one questions in assessing respondents' level of knowledge, combined scores were used to measure their level of knowledge. The level of knowledge measured on a 0-4 Likert Scale, where 0 meant for 'grossly dissatisfied' and 4 'highly satisfied' with 'partially satisfied' 1 , 'more or less satisfied' 2, and 'satisfied' 3 in between them. First the level of knowledge was assessed for every discrete question pertaining to knowledge. Then all these scores were added together to find the overall level of knowledge. The statistical analyses were performed using computer software SPSS (Statistical Package for Social Sciences) and the test statistics used to analyse the data were descriptive statistics.

\section{RESULTS}

\section{Demographic characteristics:}

Seven percent of diabetic patients were below 40 years, $23 \%$ between 40 - 50 years, $43 \%$ between 50 - 60 years and the remaining $27 \% 60$ or $>60$ years old. The mean age of the patients was 52.6 \pm 10.6 years and the youngest and oldest patients were 26 and 77 years respectively. Forty five percent of the patients were below SSC level educated, $8 \%$ SSC, $7 \%$ HSC and $13 \%$ graduate and higher level educated. Twenty seven percent of patients were illiterate (Table I).

TABLE I. Distribution of patients by demographic characteristics $(n=100)$

$\begin{array}{lcc}\text { Demographic characteristics } & \text { Frequency } & \text { Percentage } \\ \text { Age (years) } & & \\ <40 & 07 & 7.0 \\ 40-50 & 23 & 23.0 \\ 50-60 & 43 & 43.0 \\ \geq 60 & 27 & 27.0 \\ \text { Educational status } & & \\ \text { Illiterate } & 27 & 27.0 \\ \text { Below SSC } & 45 & 45.0 \\ \text { SSC } & 08 & 8.0 \\ \text { HSC } & 07 & 7.0 \\ \text { Graduate \& above } & 13 & 13.0\end{array}$

\section{Respondents' knowledge and practice about foot care}

Knowledge of the respondents was assessed by opinion seeking. Majority $92 \%$ of the respondents was of the opinion that diabetic patients should 
take medication and look after their feet regularly because minor injuries may go unnoticed, feet wounds and infection may not heal quickly or because they may get a foot ulcer which requires regular washing and dressing feet. The practice level about foot care was, however, inappreciably low as evident from the table that $52 \%$ of the respondents inspected their feet regularly, $42 \%$ washed feet with warm water, $46 \%$ trimmed toe-nails straight across, $63 \%$ measure feet before buying foot-wear and only $8 \%$ received advice from doctors before buying them (Table II).

\begin{tabular}{|c|c|c|}
\hline Respondents' foot care behaviour & Frequency & Percent \\
\hline \multicolumn{3}{|l|}{ Knowledge: } \\
\hline DM patients should take medication regularly & 92 & 92.0 \\
\hline $\begin{array}{l}\text { DM patients should look after their feet because } \\
\text { they may not feel a minor injury to their feet }\end{array}$ & 89 & 89.0 \\
\hline $\begin{array}{l}\text { DM patients should look after their feet because } \\
\text { wounds and infection may not heal quickly }\end{array}$ & 89 & 89.0 \\
\hline $\begin{array}{l}\text { DM patients should look after their feet } \\
\text { because they may get a foot ulcer }\end{array}$ & 85 & 85.0 \\
\hline $\begin{array}{l}\text { DM patients should not smoke because smoking } \\
\text { causes reduced blood circulation in the feet }\end{array}$ & 33 & 33.0 \\
\hline \multicolumn{3}{|l|}{ Practice: } \\
\hline Regular inspection of feet & 52 & 52.0 \\
\hline Regular washing of feet & 90 & 90.0 \\
\hline Washing of feet with warm water & 42 & 42.0 \\
\hline Trimming of toe nails straight across & 46 & 46.0 \\
\hline Measure feet before buying your shoes & 63 & 63.0 \\
\hline Taking advice from doctor before buying shoes & 08 & 8.0 \\
\hline Ever inspect inside of footwear & 48 & 48.0 \\
\hline Regular walking with barefoot & 60 & 60.0 \\
\hline Cleaning of nails with sharp instrument & 16 & 16.0 \\
\hline Add irritants to water before foot cleaning & 11 & 11.0 \\
\hline Wear elasticized hosiery & 37 & 37.0 \\
\hline
\end{tabular}

\#Total will not correspond to $100 \%$, because of multiple responses

\section{Respondents' opinion about foot care practice:}

Over three quarters (76\%) of the patients held the opinion that foot should be inspected daily, $6 \%$ weekly, another $6 \%$ fortnightly and $1 \%$ monthly. Majority (94\%) of the respondents was of the opinion that in case of redness/bleeding between toes they should consult with a physician first. Asked about if they had a corn or hard skin lesion, what would they do, $29 \%$ told that they would wash with antiseptic first and $7 \%$ told wash with water. Two percent of the patients were of the opinion that feet should be washed once, $10 \%$ thrice and $83 \%$ five times a day. Regarding temperature of the water used for washing of feet, over half (52\%) of the respondents thought it should be tepid water and $38 \%$ room temperature. In another question how often they should inspect inside of their footwear for objects or torn lining, $6 \%$ said once daily and $63 \%$ told each time before wearing (Table III).

TABLE III. Respondents' opinion seeking about foot care practice $\left(\mathbf{n}-100^{\#}\right)$

Respondents' opinion about foot care practice Frequency Percentage

How often feet should be inspected

$\begin{array}{lll}\text { Daily } & 76 & 76.0\end{array}$

Weekly $\quad 06 \quad 6.0$

$\begin{array}{lll}\text { Fortnightly } & 06 & 6.0\end{array}$

Monthly $01 \quad 1.0$

Not needed at all $\quad 11 \quad 11.0$

If you found redness/bleeding between toes what is the first thing you should do

$\begin{array}{lll}\text { Consult with physician } & 94 & 94.0\end{array}$

$\begin{array}{lll}\text { Not known } & 06 & 6.0\end{array}$

Even if you have never had a corn/hard skin lesion, what would you do if you had one

$\begin{array}{lll}\text { Wash with antiseptic } & 29 & 29.0\end{array}$

Wash with water

$07 \quad 7.0$

How often you think your feet should be washed

$\begin{array}{lll}\text { Once daily } & 02 & 2.0\end{array}$

$\begin{array}{lll}\text { Thrice daily } & 10 & 10.0\end{array}$

$\begin{array}{lll}\text { Five times a day } & 83 & 83.0\end{array}$

What temperature of water do you think

should wash your feet in

$\begin{array}{lll}\text { Tepid water } & 52 & 52.0\end{array}$

Room temperature $\quad 38 \quad 38.0$

How often do you think should inspect inside

of your footwear for objects or torn lining

$\begin{array}{lll}\text { Once daily } & 06 & 6.0\end{array}$

$\begin{array}{lll}\text { Each time before wearing } & 63 & 63.0\end{array}$

\#Total will not correspond to $100 \%$, because of multiple responses. 


\section{Level of knowledge about foot care in DM patients:}

Measured on Likert scale, over $8 \%$ of the respondents' knowledge about foot care was found to be highly satisfactory, $42 \%$ satisfactory, $40 \%$ more or less satisfactory and $8 \%$ poor level of knowledge. Two percent of the respondents' answer was grossly dissatisfactory (Table IV).

TABLE IV. Distribution of the respondents by level of knowledge about foot care

Level of knowledge about foot care Frequency Percentage

$\begin{array}{lll}\text { Grossly dissatisfactory } & 02 & 2.0 \\ \text { Poor } & 08 & 8.0 \\ \text { More or less satisfactory } & 40 & 40.0 \\ \text { Satisfactory } & 42 & 42.0 \\ \text { Highly satisfactory } & 08 & 8.0\end{array}$

\section{DISCUSSION}

The result of this study showed that $70 \%$ of the respondents were 50 or $>50$ years old with a female predominance (female to male ratio $2: 1$ ). Rural residents and middle class formed the main bulk of the respondents. Forty five percent of the patients were below SSC level educated and $27 \%$ were illiterate. Assessment of knowledge about foot care revealed that only $8 \%$ of the respondents' had highly satisfactory, $42 \%$ satisfactory, $40 \%$ more or less satisfactory and $8 \%$ poor level of knowledge.

Chamil \& Madawa 5 in a recent study reported that out of 110 research subjects, majority was female with age ranging between 51 and 60 years. This shows that female diabetics after the age of 50 are more often vulnerable to develop the foot problem. It is well known that diabetic foot disease occur in long standing diabetics because the pathological process takes about 10 years to develop. This situation may occur due to delayed recognition and diagnosis of diabetes mellitus. Two studies conducted abroad showed that average age of the diabetic patients was between 50 - 59 years $(40.3 \%)$ and average duration of diabetes among patients was 8.2 years. ${ }^{6,7}$ Nearly $60 \%$ of patients were from low socio-economic status and $36 \%$ were illiterate.
The findings in our study are consistent with the findings of other investigators worldwide. Patients with poor educational level and low socioeconomic status had generally lower level of knowledge of foot care, while gender and age differences were not significantly associated with the knowledge of foot care. The relationship between education and foot care among diabetic patients has been observed in similar studies in India, Iran and Pakistan where illiterate patients were the least knowledgeable. ${ }^{8-10}$ Women and those above the age of 50 were less knowledgeable about foot care, although these associations were not statistically significant. These studies showed that a very small proportion of the diabetic patients $(10.2 \%)$ had good practice of diabetic foot care, while almost half $(49.4 \%)$ had a poor practice of diabetic foot care. ${ }^{11}$

This poor level of foot care practice is in agreement with other previous studies. Some of the inadequacies of foot care practice in their subjects included non-inspection of inside of their footwear $(47.7 \%)$, non inspection of their feet $(40.9 \%)$, and $88.6 \%$ failing to get appropriate sized footwear. These poor practice of foot care may be attributed to the lack of knowledge among the respondents as $78.4 \%$ of those with poor foot care practice also had poor knowledge of foot care. This association was further corroborated as one-third (33\%) of the respondents reported lack of knowledge as greatest barrier to good foot care practice. ${ }^{12}$

The result of this study showed that a greater proportion of diabetic patients had satisfactory or more or less satisfactory level of knowledge about foot care. But lack of practice about the signs of poor foot circulation and reluctance to go to specialist when warning signs like redness/ bleeding occurs between toes may contribute to the development of skin manifestations; Importance of regular inspection of the footwear for objects or torn lining and regular inspection of the feet should also be born in mind and practiced. Great efforts would be needed by 
health care providers to motivate the diabetic patients in order to promote compliance to foot care.

\section{CONCLUSION}

The study concluded that diabetic patients are aware of their foot care. They also possess good knowledge about how to take care of those manifestations. But they are usually reluctant to bring it into practice. It is perhaps, they do not have the knowledge about the consequences if practice is lacking.

\section{REFERENCES}

1. Aldasouqi SA \& Alzahrani AS. Terminology in diabetes; an example of resistance to change. Saudi Med $J$ 2004;25(9):1289-91.

2. Ogbera $A O$, Fasanmade $O$, Ohwovoriole $A E$, Adediran O. An assessment of the disease burden of foot ulcers in patients with diabetes mellitus attending a teaching hospital in Lagos, Nigeria. Int $J$ Low Extrem Wounds 2006; 5:244-49.

3. Wild S, Roglic G, Green A, Sicree R, King H. Global Prevalence of Diabetes: Estimates for the year 2000 and projections for 2030. Diabetes Care 2004;27: 1047-53.

4. Anderson RJ, Freedland KE, Clouse RE, Lustman PJ. The prevalence of comorbid depression in adults with diabetes: a meta-analysis. Diabetes Care 2001;24(6): 1069-78.
5. Chamil VMJ \& Madawa J. A study to determine the knowledge and practice of foot care in patients with chronic diabetic ulcer. International Journal of Collaborative Research on Internal Medicine \& Public Health 2011;3(1):1205-9.

6. Ramachandran A, Snehalatha C, Baskar AD, Mary S, Kumar CK, Selvam S. Temporal changes in prevalence of diabetes and impaired glucose tolerance associated with lifestyle transition occurring in the rural population in India. Diabetologia 2004;47:860-65.

7. Heisler M, Pietee JD, Spencer M, Kieffer E, Vijan S. The relationship between knowledge of recent $\mathrm{HbA} 1 \mathrm{C}$ values and diabetes care understanding and selfmanagement. Diabetes Care 2005;28:816-22.

8. Khamseh ME, Vatankhah N, Baradaran HR. Knowledge and practice of foot care in Iranian people with type 2 diabetes. Int Wound J 2007;4(4):298-302.

9. Hasnain S \& Sheikh $\mathrm{NH}$. Knowledge and practices regarding foot care in diabetic patients visiting diabetic clinic in Jinnah Hospital, Lahore. J Pak Med Assoc 2009;59(10): 687-90.

10. Viswanathan V, Shobhana R, Snehalatha C, Seena R, Ramachandran A. Need for education on foot-care in diabetic patients in India. J Assoc Physicians India 1999;47(11):1083-85.

11. Singh N, Armstrong DG, Lipsky BA. Preventing foot ulcers in patients with diabetes. JAMA 2005;293: 21728.

12. Pollock RD, Unwin NC, Connolly V. Knowledge and practice of foot care in people with diabetes. Diabetes Res Clin Pract 2004;64:117-22. 